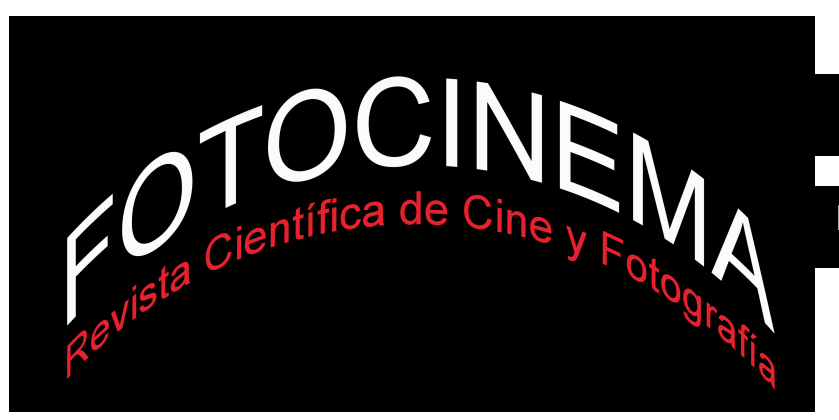

\title{
MERCADO PROHIBIDO: ANTIBIÓTICOS Y CONTRABANDO EN VERSIÓN ESPAÑOLA
}

\section{MERCADO PROHIBIDO: ANTIBIOTICS AND CONTRABAND IN SPANISH VERSION}

\author{
Raúl Rodríguez Nozal \\ Universidad de Alcalá, España \\ raulrn@uah.es
}

\author{
Antonio González Bueno \\ Universidad Complutense de Madrid, España \\ agbueno@ucm.es
}

\section{Resumen:}

Con las limitaciones redentoras y moralizantes propias del franquismo, y las derivadas de la censura existente en aquellos años, la película española Mercado Prohibido (Xavier Setó, 1952) se nos presenta como una interesante fuente para analizar el problema del contrabando de antibióticos durante este período. Las referencias a este asunto son abundantes y muy explícitas: necesidad de conservar estos productos en ambiente refrigerado, lugar de procedencia de estas sustancias (EE.UU.), principales antibióticos existentes en torno a 1951 (penicilina, estreptomicina y cloranfenicol), existencia de robos de antibióticos en hospitales, así como de adulteraciones y falsificaciones, o claras alusiones a las políticas españolas promovidas con el ánimo de acabar con este mercado ilícito, en concreto las relativas a la fabricación de antibióticos en España, circunstancia que queda claramente explicitada en este largometraje, y que parece querer ser utilizada como herramienta propagandística para tratar de mostrar las excelencias de nuestro progreso industrial y de nuestro modelo de economía autárquica.

\begin{abstract}
:
The Spanish film Mercado Prohibido (Xavier Setó, 1952) is an interesting source for analyzing the problem of contraband of antibiotics during the Franco dictatorship even with the redemptive and moralizing limitations inherent to Francoism, and those derived from the censorship that existed in those years. The references to this subject in the film are abundant and very explicit: the need to preserve these products in a refrigerated environment, the place of origin of these substances (United States), the main antibiotics existing around 1951 (penicillin, streptomycin and chloramphenicol) or the existence of theft of Antibiotics in hospitals, as well as adulterations and falsifications. The film also presents the Spanish policies promoted with the aim of ending this illicit market, specifically those relating to the manufacture of antibiotics in Spain, a circumstance that seems to be used as a propagandistic tool to try to show the excellence of our industrial progress and our model of autarkic economy.
\end{abstract}

Palabras clave: Mercado Prohibido; Xavier Setó; Antibióticos; Contrabando; Franquismo.

Keywords: Mercado Prohibido; Xavier Setó; Antibiotics; Contraband; Francoism. 
Cómo citar: Rodríguez Nozal R. y González Bueno, A. (2017). "Mercado Prohibido: antibióticos y contrabando en versión española”. Fotocinema. Revista científica de cine y fotografía, $\mathrm{n}^{0}$ 15, pp. 283-302. Disponible: http://www.revistafotocinema.com/

\section{Introducción}

Con las limitaciones propias que impondrá la censura durante los años del franquismo, el cine de este período se convierte en testimonio visual de la sociedad española y sus preocupaciones. La aparición de los antibióticos, y su oscuro mercado, no podía pasar desapercibido para esta manifestación cultural, si bien el empleo de quimioterápicos está presente desde las primeras cintas de cine mudo ${ }^{1}$, la utilización -y el mercado negro- de los antibióticos en el mundo cinematográfico será coetáneo a su empleo tras los años de la Segunda Guerra Mundial. Una película clásica sobre esta temática es El Tercer Hombre (Third Man, Carol Reed, 1949), realizada a partir de una novela y un guion escritos por Henry Grahame Green, estrenada en las salas españolas en 1950 (García Sánchez, García Sánchez \& Merino Marcos, 2006).

\section{Mercado Prohibido: descripción de la fuente}

Mercado prohibido es la primera película dirigida por el catalán Xavier Setó (1926-1969), una de las pocas realizada por este cineasta en España antes de partir a Italia, donde trabajó para Cinecittà ${ }^{2}$ El guion fue construido por Julio Coll i Claramunt (1919-1993)3, quien trabajó también como asesor

\footnotetext{
${ }^{1}$ Suele señalarse $A$ trade secret, dirigida en 1915 por William F. Haddock (1877-1969), como la primera incursión en el tema (García Sánchez \& García Sánchez, 2004).

2 Xavier Setó (Lérida, 1926-Madrid, 1969), dirigió casi una treintena de películas entre 1952 (Mercado prohibido) y 1969 (El fantasma asesino), buena parte de ellas producciones de Cinecittà (Italia), para la que trabajó entre 1958 y 1969; entre sus obras más comentadas se encuentra Saeta Rubia, rodada en 1956, el primero de los dos proyectos cinematográficos en los que participará Alfredo Di Stéfano (1926-2014) (Simón Sanjurjo, 2012).

3 Julio Coll i Claramunt (Camprodón, Barcelona, 7/04/1919 - Madrid, 17/01/1993), director, guionista y productor de cine, realizador de televisión, escritor, periodista y crítico musical y teatral (Crusells, 2009).
} 
artístico, y José Germán Huici (1922-2001)4 La producción corrió a cargo de IFI Producción S.A., la empresa cinematográfica fundada, en 1949, por Ignacio F. Iquino siguiendo los planteamientos empresariales del studiosystem; para ello dispuso de sus propios estudios en el Paralelo de Barcelona, activos entre 1950 y $1970^{5}$.

Con una duración de 76,07 minutos y un metraje de 2.600 metros $^{6}$, Mercado prohibido fue rodada en blanco y negro, con exteriores en Barcelona, entre el 18 de febrero y el 30 de abril de 1952; contó con un presupuesto de 2.049.800 pesetas (tabla 1$)^{7}$.

\begin{tabular}{|l|l|l|l|l|}
\hline \multicolumn{4}{|c|}{ Tabla 1. Presupuesto de Mercado prohibido } \\
\hline $\begin{array}{l}\text { personal artístico: } \\
\text { personajes principales }\end{array}$ & 190.000 ptas. & $\begin{array}{l}\text { personal artístico: } \\
\text { personajes secundarios }\end{array}$ & 26.000 ptas. \\
\hline extras, figuración y dobles & 45.000 ptas. & personal técnico & 262.000 ptas. \\
\hline personal administrativo & 21.000 ptas. & obra y guion & 92.000 ptas. \\
\hline música & 107.000 ptas. & dibujos & 5.600 ptas. \\
\hline estudios & 256.000 ptas. & decorados en estudios & 330.500 ptas. \\
\hline ambiente & 100.000 ptas. & vestuario y maquillaje & 60.500 ptas. \\
\hline $\begin{array}{l}\text { material, película virgen y } \\
\text { foto fija }\end{array}$ & 340.040 ptas. & laboratorios & 67.660 ptas. \\
\hline desplazamientos & 59.500 ptas. & seguros & 57.000 ptas. \\
\hline
\end{tabular}

4 José Germán Huici (Tudela, Navarra, 1922 - Madrid, 2001), editor de la revista Cine Arte; desde 1946 se instaló en Barcelona, donde comenzó a colaborar en la revista Cinema y trabajó como guionista para el productor y director Ignacio F. Iquino; desde finales de los cincuenta desarrolló una fructífera colaboración con el director Julio Coll (Agencia EFE, 2001).

5 Ignacio Farrés Iquino (Valls, Tarragona, 25/10/1910 - Barcelona, 29/04/1994), fue uno de los directores y productores más prolíficos del cine español; su obra ha sido recientemente analizada por A. Comas Puente (2002).

6 Carlos Grande. 1952. "Cuadro técnico artístico y datos finales [de Mercado prohibido]. Madrid, 30/04/1952 (Archivo General de la Administración [AGA], (03) 121.002, caja 36/04730).

7 Carlos Grande. 1952. Ficha de producción de Mercado prohibido, presentada por Producciones Iquino. Barcelona, 30/04/1952. Carlos Grande actúa en su calidad de Director general de Producción (AGA, (03) 121.002, caja 36/04730). 
El título inicialmente propuesto para la película fue 400.000 unidades. Con él se solicitó, el 23/01/1952, el permiso de rodaje9, que fue concedido el 11 de febrero ${ }^{10}$. Sólo tres días después se pedía el cambio de título por el de Mercado prohibido"1, el cual fue incorporado a la ficha oficial de rodaje el 19/02/1952 ${ }^{12}$. No parece que el guion tuviera problemas con la censura; no obstante, en el apartado de observaciones del expediente de rodaje, quedó anotado:

Para evitar ulteriores inconvenientes de censura el director deberá cuidar la realización de escenas de efusiones amorosas, así como también la intervención del inspector de policía cuya actitud deberá ser digna y adecuada en todo momento ${ }^{13}$.

Efectivamente, la relación del protagonista, Germán (Manuel Monroy), con Adela (Silvia Morgan), su esposa, más parece la propia de un amor fraternal que matrimonial y los acercamientos físicos de Germán a Lola, 'La Lucky'

8 "Presupuesto de la película Mercado prohibido". (AGA, (03) 121.002, caja 36/03429. Además de los guionistas y del director, mencionados anteriormente, en la película participaron: Emilio Foriscot (fotografía, 'operador', 35.00o pesetas), Manuel Bengoa (jefe de producción, 25.000 pesetas), José María Nunes (ayudante de dirección, 10.000 pesetas), Clemente Manzano (ayudante operador, 15.00o pesetas), Amadeo Viñals (ayudante de producción, 6.000 pesetas), Julia S. de la Fuente (secretaria de rodaje, 4.500 pesetas), Miguel Llull (decorador, 35.000 pesetas), Ramón Quadreny (montador, 20.000 pesetas), Antonio García (foto-fija, 6.00o pesetas), Antonio Samso (regidor, 4.500 pesetas), Augusto Algueró (música, 107.000 pesetas), Ojos negros (vestuario, 60.500 pesetas), Manuel Manteca (maquillador, 11.00o pesetas) y Parlo Films (sonido, 28.000 pesetas). El grupo ha sido calificado por F. Sánchez Barba (2007, p. 266) como el "equipo técnico estable de la productora [que] ayudaba a conformar cierto estilo visual especialmente característico de la ficción negra barcelonesa"; este autor también cita otros nombres, probablemente miembros de plantilla de la productora: Carlos Grande (director general de producción), Antonio Cánovas (montaje), Juan García (ingeniero de sonido), Pilar Serrano (ayudante de montaje), Isaac (muebles y atrezzo) y J. Olivella (complementos).

9 Instancia de Carlos Rodríguez González, director general de Producciones Iquino, domiciliada en Barcelona, Marqués del Duero 106, dirigida al Director general de Cinematografía y Teatro. Barcelona, 23/01/1952 (AGA, (03) 121.002, caja 36/04730).

10 Permiso de rodaje emitido por la Dirección General de Cinematografía y Teatro (Ministerio de Información). Madrid, 11/02/1952 (AGA, (O3) 121.002, caja 36/o3429). El permiso de doblaje fue obtenido el 18/06/1952 (AGA, (o3) 121.002, caja 36/03429).

${ }_{11}$ Instancia de Carlos Grande (Producciones Iquino) dirigida al Director general de Cinematografía. Barcelona, 14/02/1952 (AGA, (03) 121.002, caja 36/04730).

12 "Con esta fecha queda autorizado el cambio de título del presente permiso de rodaje por el de 'Mercado prohibido". Madrid, 19/02/1952 (AGA, (03) 121.002, caja 36/o3429).

13 Permiso de rodaje emitido por la Dirección General de Cinematografía y Teatro (Ministerio de Información). Madrid, 11/o2/1952 (AGA, (03) 121.002, caja 36/03429). 
(Isabel de Castro), en ningún momento recuerdan a los habituales entre amantes. También se respeta escrupulosamente el rol asignado a la autoridad policial, bosquejado como una persona inteligente, con principios morales, compasivo y humano, según los preceptos del nacionalcatolicismo.

Los censores del guion fueron Joaquín Argamasilla de la Cerda y Elio (19051985), marqués de Santacara, quien ejercía la presidencia de la Junta de Clasificación y Censura (Aracena Badillos, 2007), el escritor y productor José María Alonso-Pesquera y Cendra (1905-1991), marqués de Alonso-Pesquera, a la sazón presidente del grupo nacional de cooperativas cinematográficas ${ }^{14}$, y el dominico Antonio García Figar (n. 1880), crítico habitual de la revista falangista Primer Plano (Vandaele, 2015, pp. 58, 331-332). Los censores no sugirieron cambios en el guion, clasificando la película como "Autorizada todos los públicos”15.

Mercado prohibido fue estrenada en Barcelona, el 20 de junio de 1952, en Madrid el 23 de marzo de 1953, y posteriormente se distribuyó por toda la geografía española. No fue una película de éxito y sólo permaneció diez días en cartel en las salas de Barcelona y Madrid donde fue estrenada ${ }^{16}$. El Anuario del Cine Español ofrece una breve síntesis de la obra:

Contrabando y venta abusiva de antibióticos. El jefe de una banda de traficantes se ve obligado a implorar entre todos aquellos que engañó y traicionó muchas veces, unos gramos de la droga que salvará a su hijo. Es detenido por la policía, que le permite acudir al lecho de su hijo antes de ingresar en prisión (Anuario del Cine Español, 1955, p. 225).

La película se incluye dentro de un conjunto de obras, realizadas en la Cataluña de los años 1950, cuyo rasgo común es la pertenencia al género

\footnotetext{
14 Ocupó la presidencia del Grupo entre 1951 y 1953 (Vandaele, 2015, p. 325).

15 Expediente 11306 de la Junta de Clasificación y Censura. Madrid, 19/o8/1952 (AGA, (o3) 121.002, caja 36/03435). No obstante, es probable que, con posterioridad, se modificara esta calificación ya que los productores solicitaron, en abril de 1953, que fuera declarada como "Apta para todos los públicos" en lugar de "Apta para mayores de 16 años": "Que al no ser ésta película apta para menores tenemos grandes dificultades para su normal explotación. Por ello a V.I. Suplica Qué se digne la revisión de nuestra película mediante los costes o variaciones aconsejados por la Junta pueda ser declarada “Apta para todos los públicos". Madrid, 23/04/1953 (AGA, (03) 121.002, caja 36/03429).

${ }_{16}$ Hoy día es una película difícil de visionar, nosotros hemos consultado el ejemplar conservado en la Filmoteca Española [DV-02857]. Agradecemos a José Luis Estarrona las facilidades para poder acceder a este largometraje.
} 
negro/policiaco, potenciada por el éxito de los filmes estadounidenses que llegaron, en oleada a la España de los años 1940 (Sánchez Barba, 2007, pp. 265-269), con las evidentes limitaciones redentoras y moralizantes propias del franquismo. La obra recoge, con la cercanía que supone trasladar el mundo social en que transcurre, un magnífico tapiz realista de la situación social del franquismo.

En opinión de Pablo Ruiz Gijón, Mercado prohibido sirvió como fuente de inspiración para el largometraje argentino Mercado negro (Kurt Land, 1953), donde también se aborda el asunto del contrabando de sustancias medicinales, en este caso durante el peronismo. Ambas películas tienen bastantes nexos en común: ambigüedad moral de algunos de los personajes, que alternan "momentos de altruismo y honestidad con otros caracterizados por la más absoluta degeneración moral”, papel protagonista de las fuerzas de seguridad como garantes del orden establecido y mensaje ejemplarizante, dirigido a la ciudadanía, sobre lo nocivo que es este tipo de práctica ilegal. Los protagonistas son doblemente castigados; por un lado con la cárcel y, por otro, con la culpa, en este caso mucho más acentuada en el caso de Mercado negro, donde el desenlace es más trágico que en Mercado prohibido. La diferencia fundamental entre ambas obras, residiría en la orientación y la trascendencia que se querría transmitir a la ciudadanía; por un lado el redentorismo católico de Mercado prohibido y, por otro, el concepto laicista que según Rubio Gijón:

toma el Estado peronista como principio del que proviene la ley y la moral, como ente benefactor y paternalista, que no sólo vela por el bienestar ciudadano, sino que también concibe la regeneración del delincuente como parte indispensable de su doctrina -justicialismo-. (2014, pp. 242-248).

\section{3.- Entre la realidad y la ficción: el contrabando de antibióticos en la España autárquica}


No nos compete realizar un análisis exhaustivo en torno al carácter moralista de Mercado prohibido ${ }^{17}$, explícitamente presente a lo largo de todo el relato, que lleva al contrabandista a la necesidad de modificar sus hábitos de vida y expiar sus pecados para salvar la vida de su propio hijo, una "rehabilitación moral” del delincuente tan del gusto de la ética franquista. Tampoco analizaremos las características cinematográficas de la obra, poco elogiada por los críticos (Comas Puente, 2002, pp. 238-239). Nuestro interés se centra en estudiar la pieza en cuanto manifestación de la situación social que, del mercado y empleo de los antibióticos, se mostraba en pleno franquismo.

Mientras que en el clásico El Tercer Hombre, desarrollado en la Viena ocupada por los vencedores de la II Guerra Mundial, el argumento se centra en las investigaciones llevadas a cabo por el protagonista a fin de aclarar las extrañas circunstancias que rodearon la muerte de su amigo, por supuesto, con el mercado negro de penicilina envolviendo a los personajes y tejiendo la trama principal, en Mercado prohibido el contrabando de antibióticos es el protagonista absoluto de la película; las referencias son abundantes, explícitas y ajustadas a la realidad española de aquellos años. Las palabras que preceden al inicio de la proyección aluden directamente a esta situación y constituyen una declaración de intenciones respecto de lo que se pretendía con esta película:

Una película cuya acción transcurre durante el reciente período de la postguerra europea, y que pone en evidencia -por primera vez en nuestro cine- una de las formas más despiadadas de contrabando.

La ciencia moderna, con sus trascendentales descubrimientos médicos, ha creado, a la par que una esperanza para muchos enfermos considerados hasta ahora incurables, una angustia nueva que está conmoviendo a la humanidad: saber que existe algo que puede curarle y no hallarlo en el mercado.

Contra todos aquellos que se enriquecen a costa del dolor de los demás, va dirigida esta película.

\footnotetext{
17 "Esta película española es un violento alegato contra los que comercian con el dolor humano: concretamente, contra los especuladores en el tráfico ilícito de antibióticos. Esta intención moralizadora de sus realizadores constituye precisamente el más alto valor de la cinta ..." $A B C, 19 / 06 / 1953$.
} 
El inicio del filme nos remite a un entorno marítimo-pesquero donde, de acuerdo con el guion, queda ya evidente la trama:

Van procediendo al arrastre en silencio, hasta que empieza a salir del agua el voluminoso contenido de las redes (...). En medio de una exigua pesca, entre el brillo de unas sardinas, hay diez cajas de medio metro de lado, de cartón. Rápidamente los hombres abren la red y echan las cajas sobre la arena. Uno de los envases de cartón, al desprenderse de la red se desgarra, desparramando su contenido. Salen rodando docenas de tubos de penicilina sobre la arena. La cámara destacará uno de los pequeños envoltorios en los que se lee: PENICILINA - U.S.A. ${ }^{18}$

El visionado de la película desvela algunos de los problemas cotidianos en torno al empleo de la penicilina en España a comienzos de los años cincuenta. Ya en las primeras secuencias de la cinta se presenta a Germán (Manuel Monroy)19, un empresario supuestamente modélico, que en realidad se dedica al contrabando de penicilina, para lo cual emplea su almacén frigorífico en el que conservar un producto aún termolábil, el mismo espacio en que se almacenaba el pescado, negocio que esta organización criminal utilizaba como tapadera.

A Germán le acompaña en el negocio Daniel (Carlos Otero), defensor a ultranza del enriquecimiento a cualquier precio, así como otros secuaces con un umbral ético similar al de Daniel; son personajes de difícil redención, condenados a pagar por sus pecados y a sufrir las consecuencias de su baja catadura moral. Es el caso de Luis, partidario de falsificar la penicilina con el fin de obtener mayores beneficios, una práctica habitual durante aquellos

18 Julio Coll, José Germán Huici. 1951. "Argumento, guion y diálogos [de Mercado prohibido]”. Barcelona, 12/11/1951 (AGA, (o3) 49.02, caja 9714).

${ }_{19}$ Completan el elenco: Isabel de Castro (Lola, "la Lucky"), Silvia Morgan (Adela), Carlos Otero (Daniel), Alfonso Estela (Miguel Ángel), Manuel Gas (Inspector Lérida), Manuel de Mozos (Adrián), Flores García (cerero), Ángel Valdivieso (Luis), Francisco Albiñana (pescador). Los actores que encarnaron a los tres personajes principales, Germán, Lola y Miguel Ángel cobraron, cada uno de ellos, 40.0oo pesetas por su actuación; el actor que dio vida al Inspector Lérida 30.000 pesetas; Silvia Morgan y Carlos Otero recibieron, cada uno de ellos, 20.000 pesetas. Los sueldos de los actores secundarios fluctuaron entre las $4.000 \mathrm{y}$ las 8.000 pesetas; además hubo un monto de 15.000 pesetas para extras y dobles que intervinieron en la película ( $c f$. Carlos Grande. "Presupuesto de la película 'Mercado Prohibido"”. Barcelona, 30/04/1952. AGA, (03) 121.002, caja 36/03429). 
años de escasez, de la que se hace eco la prensa diaria ${ }^{20}$ y que ya había sido manejado como recurso argumental en El tercer hombre para tratar de explicar cómo muchos niños con meningitis terminaban muriendo o, en el mejor de los casos, acababan sus días con deficiencias mentales graves de carácter irreversible.

Desde el principio, se quiere mostrar a un jefe, Germán, diferente a sus subordinados, capaz de distinguir entre el bien y el mal, y de mostrarle a Luis el camino correcto: "La penicilina que nosotros importamos resulta cara, ilo sé!... iPero es buena y cura!... Y esto que intentas es un crimen!... ¿Entendido?...”21. La desahogada posición económica de Germán, conseguida gracias al lucrativo negocio del contrabando de antibióticos, contrasta con su discurso de servicio público, algo que es capaz de defender incluso ante el propio inspector de policía:

Germán (G): [la penicilina] escasea terriblemente y nuestros enfermos están necesitados de ella. Quien sea el que la proporciona, es un benefactor ${ }^{22}$

Inspector (I): ¿Al precio que sea?

G: La cuestión es que se encuentre en el mercado

I: ¿Crees que ella [la esposa de Germán] opinaría igual que tú?

Tras las primeras remesas de penicilina llegadas a España (Rodríguez Nozal, 2011), a partir de marzo de 1944, y el acuerdo establecido con los Estados Unidos meses después (Agencia EFE, 1944, p. 15), se articuló un mecanismo destinado a regular la importación, distribución y empleo de este escaso y valioso medicamento. Para ello, el Consejo Nacional de Sanidad nombró una comisión técnica, el Comité Nacional de la Penicilina, presidida por Carlos Jiménez Díaz (1898-1967), de la que también formaron parte el bacteriólogo

20 "Venta de penicilina de contrabando. La Dirección General de Sanidad anuncia que tiene noticias de que algunos comerciantes desaprensivos venden a las farmacias frascos de penicilina de una marca americana, simulando en su presentación un aspecto legal en los envases. Como consecuencia de estos hechos previene a los farmacéuticos y al público que dichos frascos, con etiquetas falsas, son productos de contrabando, no controlados por los servicios técnicos correspondientes, y que su precio es muy superior a los autorizados". $A B C$, $12 / 06 / 1954$.

${ }^{21}$ En el guion original Germán se mostraba aún más explícito: "que no vea yo a quien se la vendes!" (Julio Coll, José Germán Huici. 1951. Op. cit. AGA, (03) 49.02, caja 9714), una frase que, finalmente, no apareció en la película.

22 "Merece más que felicitaciones", frase incluida en el guion y eliminada de los diálogos o en la fase de montaje (Julio Coll, José Germán Huici. 1951. Op. cit. AGA, (03) 49.02, caja 9714). 
Gerardo Clavero del Campo (1895-1972), el farmacéutico Nazario Díaz López (1902-1988) y el dermatólogo Enrique Álvarez Sainz de Aja (1884-1965)23. Poco tiempo después, en 1946, las autoridades sanitarias centralizaron la penicilina en un depósito central, ubicado en el Colegio Oficial de Farmacéuticos de Madrid. Esta circunstancia se recogió en el guion de la película: Germán acude a este organismo farmacéutico en busca de antibióticos para su hijo y allí le informan que el suministro de estas sustancias ha sido robado; es evidente que muchas personas morirán, por lo que acaba sintiéndose "acusado por toda aquella gente". Finalmente este pasaje no se incluyó en el metraje, sin duda porque resultaba anacrónico para 1950/1951, momento en el que presumiblemente se desarrolla la acción. Desde comienzos de 1947 todas las farmacias españolas, que reunieran las debidas condiciones de almacenaje y conservación, básicamente un frigorífico, quedaron autorizadas para dispensar libremente este antibiótico ${ }^{24}$.

Es evidente que, a pesar de esta disposición, que más que solucionar el problema trataba de enmascararlo con una simple declaración de intenciones de carácter propagandístico, la penicilina seguía sin llegar con fluidez a las farmacias, para regocijo de traficantes y especuladores, que se convertían en imprescindibles para quienes, de manera desesperada, buscaban la 'droga mágica'. En este sentido, el largometraje Mercado prohibido es utilizado como herramienta propagandística con el fin de mostrar las excelencias de nuestro modelo de economía autárquica $\mathrm{y}$, también, de nuestro progreso industrial en materia de antibióticos. Dos conversaciones ilustran esta situación; la primera es la mantenida entre Germán y uno de sus habituales compradores, un practicante que rechaza el pedido habitual ante la promesa de penicilina para todos los españoles realizada por el Gobierno:

${ }_{23}^{23}$ La Vanguardia Española, 21/o9/1944, 1944; ABC, 21/09/1944. También formó parte de este Comité de la Penicilina, entre 1943 y 1946, el médico Eduardo Ortiz de Landázuri (Olagüe de Ros, 2001). El mecanismo de distribución aparece descrito en la prensa profesional ([Redacción], 1946).

24 Orden de 30/12/1946, firmada el Director general de Sanidad, "por la que se autoriza la venta libre de aquellas cantidades de 'Penicilina' que no se considere indispensable para las atenciones de este Servicio, tanto en Madrid como en los depósitos instalados en provincias". $B O E, 4 / 01 / 1947$. 
Practicante (P): Pues, bien. No puedo admitir su mercancía. No me la envíe Germán (G): ¿̇por qué?

P: No me interesa, ya se lo he dicho. Se espera un suministro oficial a 24 pesetas

G: Pero ya sabe usted que esos suministros oficiales son exiguos. No nos han afectado nunca. Nuestros precios se mantendrán altos iLo sostendremos nosotros! iPodemos hacerlo!

P: Lo siento. iCreo que esto se acabó! Sé que el Gobierno ha asegurado el reparto a todas las farmacias del país y esto terminará con los precios de ustedes

G: iÓigame! iTengo aquí un cargamento que he pagado a buen precio! iY usted se comprometió conmigo!

P.: Lo lamento. No puedo hacer nada

G: Oiga. He comprometido cerca de un millón ${ }^{25}$ en este asunto”. iOiga! iOiga!

En esta conversación se alude a lo abultado del precio de este producto de contrabando. Según la prensa española de la época, en los años cuarenta la penicilina se vendía, en el 'mercado prohibido', por un precio unas veinte veces mayor del legalmente establecido. Valga un ejemplo: en el verano de 1945, una banda de traficantes en Bilbao fue detenida cuando trataba de vender este producto al precio de 300 pesetas por cada envase de 100.000 Unidades Internacionales (U.I.) ${ }^{26}$. Las primeras remesas legales de penicilina procedente de los Estados Unidos que llegaron a España, en 1944, fueron dispensadas a 75 pesetas por envase de 100.000 U.I. En 1946 el precio ya se había logrado bajar hasta las 25 pesetas (Volpone, 1946) y, en 1948, se situaba entre las 12 y las 14 pesetas ([Redacción], 1948), aunque en el diálogo anterior se mencione un precio de 25 pesetas.

Como señalamos, la penicilina solía medirse en Unidades Internacionales; la equivalencia fue establecida en octubre de 1944: un millón de U.I. equivalía a 600 miligramos de penicilina purificada ${ }^{27}$. Tal y como nos enseña Florencio

25 En el guion original la cifra aludida no era un millón sino cien mil pesetas Julio Coll, José Germán Huici. 1951. Op. cit. AGA, (03) 49.02, caja 9714.

26 "Detención de traficantes clandestinos de penicilina". La Vanguardia Española, 30/08/1945. La multa impuesta a cada estraperlista detenido fue de 10.000 pesetas.

${ }_{27}$ Inicialmente se utilizó la "Unidad Oxford" (U.O.), una unidad arbitraria establecida por el 
Bustinza, una de las personas con mayores conocimientos de antibióticos en la España de los años cuarenta y cincuenta $^{28}$, este tipo de unidad venía definida

por la actividad específica contenida en o,6 de millonésima de gramo del Estándar Internacional de Penicilina, debiendo estimarse esa actividad frente a la estirpe de Staphylococcus aureus núm. 6571 del National Collection of Type Cultures de Inglaterra, o de la estirpe núm. 209-F del Food and Drug Administration de los Estados Unidos (Bustinza, 1949a).

Aunque es obvio que la cantidad de penicilina que se necesitaba para atajar una enfermedad bacteriana era distinta en función de diferentes factores (tipo de enfermedad, edad del enfermo y otras circunstancias), el propio Alexander Fleming (1881-1955) mantuvo que, incluso en el caso de septicemias graves, era suficiente con un tratamiento global de un millón de U.I., es decir, seiscientos miligramos en inyecciones de 100.000 U.I. (Fleming, 1948). El médico español José Álvarez Sierra (1888-1980), en un texto inicial, publicado en 1944, recomendaba la inyección intravenosa de 5.000 a 10.000 de U.O. por hora o "en inyecciones espaciadas, de 120.000 a 240.00o por día"; para la vía intramuscular se solían emplear ampollas de un centímetro cúbico, con 5.000, 10.000, 25.000 y 100.000 U.O.; también señalaba que, en algunas septicemias, se habían llegado a utilizar 2.465.000 U.O. en un período de siete días (Álvarez Sierra, 1944, pp. 101-102).

El otro diálogo al que nos referíamos es el mantenido entre Germán y un cerero que, entre cirio y cirio, vendía al por menor la penicilina de contrabando que le suministraba esta banda, incluso la enviaba a Turquía oculta en el interior de las velas:

Cerero (C): Lo siento. Tú lo sabes tan bien como yo. Este negocio ha llegado a su fin. La intervención oficial nos ha hundido

grupo de Florey en 1940; ellos la definieron como "la cantidad de penicilina contenida en un centímetro cúbico de una determinada disolución de penicilina en un tampón de fosfatos, y siendo su potencia tal, que 0,01 a 0,02 de unidad por centímetro cúbico inhibe el crecimiento de cepas sensibles de estafilococos. En opinión de Florencio Bustinza, "si consideramos que la penicilina pura cristalizada tiene 1.650 U.O. de actividad por mg., un sencillo cálculo nos demuestra que esos 0,000.000.6 g. de penicilina pura equivalen en actividad a la U.O." (Bustinza, 1945, pp. 184-185).

${ }^{28}$ Sobre Florencio Bustinza, véase Fonfría Díaz (2013), Córdoba (1982) y Bellot Rodríguez (1982). 
Germán (G): Aún no. Yo sé de muchos que andan detrás de eso

C: Peor para ellos, la baja de precios es inminente, y supongo que te habrás enterado que dentro de muy poco el Estado inaugurará una gran fábrica de antibióticos. Quizá sea la más importante de Europa. Esperemos, pues, a que los abnegados hombres de ciencia descubran otra medicina prodigiosa para curar a la Humanidad. Y que escasee, como hasta ahora la penicilina, para que nosotros podamos seguir viviendo.

En el guion original las palabras del cerero eran más explícitas, aludiendo directamente a la fábrica de penicilina que la Compañía Española de Penicilina y Antibióticos (CEPA) acabaría abriendo en Aranjuez ${ }^{29}$. Pero no era ésta única fábrica de antibióticos que se estaba instalando en suelo español, a la mencionada en el guion, habría que añadir la establecida en León por el consorcio Antibióticos S.A., ambas abiertas en fechas coetáneas a la narración recogida en este largometraje ${ }^{30}$. Un detalle que nos muestra hasta qué extremo trataron de ser cuidadosos los guionistas y productores de la película.

Pese al mensaje patriótico y tranquilizador que la cinta intentaba transmitir, en 1950 el mercado negro de penicilina seguía campando a sus anchas en España. Hasta la prensa profesional farmacéutica se hacía eco de esta actividad delictiva, ese 'nuevo malo', que los españoles estaban conociendo gracias a la película El tercer hombre, un personaje que no era ni comunista, ni espía, ni atracador de bancos, ni truculento vampiro, sino el estraperlista de medicamentos que robaba "de los hospitales medicamentos antibióticos para traficar con ellos en el negrísimo mercado que las circunstancias crearon en la vieja corte de los valses y de las reverencias" ([Redacción], 1950). El 'tercer hombre', el personaje bosquejado por Henry Graham Greene (1904-1991) en 1949, había sustituido al 'malo' del Far West; pero, en

\footnotetext{
29 "Peor para ellos... Dentro de un mes el Estado inaugurará una fábrica de penicilina en Aranjuez” (Julio Coll, José Germán Huici. 1951. Op. cit. AGA, (03) 49.02, caja 9714).

${ }^{30}$ La anómala situación del comercio ilegal de la penicilina trató de ser resuelta a través del Decreto de 1/09/1948 "por el que se declara de 'interés nacional' la fabricación de penicilina y se abre un concurso, para llevarla a cabo, entre entidades españolas" (BOE 6/10/1948). El concurso fue resuelto (Decretos de 17/06/1949. BOE 11/o8/1949) en favor de dos consorcios empresariales: Antibióticos, S.A. y Compañía Española de Penicilina y Antibióticos (CEPA) (Santesmases, 1999; Rodríguez Nozal, 2004; Santesamases, 2011; González Bueno \& Rodríguez Nozal, 2012).
} 
ocasiones, ni siquiera eran contrabandistas, simplemente farmacéuticos que sustituían o adulteraban penicilina, traidores "a una noble causa", cuya "falta grave y sin defensa, debe ser castigada con el máximo rigor” ([Redacción], 1951).

Entre los finales de la década de 1940 y los primeros años de 1950, en el momento en el que se desarrolla la acción de Mercado prohibido, se seguía traficando con penicilina ${ }^{31}$, pese a las medidas político-económicas tomadas por el Gobierno del general Franco para establecer un duopolio de su producción bajo criterios 'semi-autárquicos'. Por otro lado, también existían medicamentos a base de penicilina extranjera, legalmente registrados a partir del año 1945 que, o bien se fabricaban en España utilizando patentes foráneas o, simplemente, eran elaborados por laboratorios españoles a partir de materias primas propiedad de industrias extranjeras. En este último caso los centros nacionales sólo proporcionaban el desarrollo galénico y el envasado. Por si fuera poca competencia para la penicilina de producción nacional, además existía la creencia popular de que la penicilina española era de peor calidad que la extranjera:

Los propios enfermos, a quienes la superstición de un estúpido exotismo ha llevado a colaborar con toda suerte de tahúres en el contrabando de antibióticos. Es más, con una estupidez rayana en la mostrenquería, se ha mantenido en el mundillo criminal del bulo la especie de que los productos nacionales eran de inferior calidad y eficacia a sus hermanos venidos del extranjero. (Redacción, 1958).

La situación era, desde luego, paradójica. Existía una penicilina de producción nacional, a un elevado precio, protegida por las autoridades ${ }^{32}$;

${ }^{31}$ Por señalar algún ejemplo, véanse las noticias aparecidas en $A B C$ los días 7/07/1950, 18/07/1952, 11/01/1953, 21/10/1953, 25/10/1953, 08/01/1955, 06/05/1955, 22/07/1955, 18/07/1956, 28/10/1956, 17/11/1956, y 12/07/1957.

32 "La Dirección General de Sanidad, ante el recrudecimiento del contrabando de penicilina, ha hecho pública una nota en la Prensa del peligro de adquirir este producto, de cualquier procedencia, cuando está incontrolado desde el punto de vista sanitario. Farmiberia, S.A., representante en España de la Merck \& Co. (North América), adhiriéndose a las declaraciones de la Dirección General de Sanidad, hace constar, asimismo, públicamente, que aquella penicilina que no haya sido importada legalmente de la procedencia de su propia marca, no ofrece la garantía de su procedencia y calidad. La única penicilina Merck existente en nuestro mercado, que ofrece plena y total garantía, es la fabricada por 'Compañía Española de Penicilina y Antibioticos, S.A.' (C.E.P.A.), con patentes y procedimientos Merck, 
una buena cantidad de medicamentos con penicilina procedente del extranjero, autorizados en su comercialización por el Ministerio de la Gobernación, a un precio sensiblemente inferior; y un lucrativo y oscuro volumen de penicilina fuera de los cauces oficiales, procedente del contrabando.

A la penicilina pronto se unirían otros antibióticos con los que traficar. En Mercado prohibido se nos avanzan dos de ellos: la estreptomicina, descubierta en 1943 gracias al trabajo desarrollado por un grupo de investigación dirigido por Selman Abraham Waksman (1888-1963) en el Laboratorio de Microbiología de la Rutgers University (New Brunswick, EE.UU.) (Bustinza, 1948)33, y el cloranfenicol (cloromicetina), utilizado en terapéutica a partir de $1947^{34}$.

La estreptomicina pronto se mostró eficaz contra la tuberculosis, enfermedad resistente a la penicilina. Probablemente era este el mal que aquejaba a un pescador que acudía a los contrabandistas de Mercado prohibido en busca de ayuda: "necesito unos gramos de estreptomicina, sé que vosotros la tenéis", una frase algo más compleja en el guion original de la película, donde Daniel (uno de los contrabandistas) le pregunta al pescador si es que no hay penicilina en las farmacias. El pescador le dice que no le ha hecho efecto, que necesita estreptomicina. Daniel miente, dice no disponer de ese material y añade que, en cualquier caso, no serviría de nada porque "vosotros creéis que esas drogas lo curan todo y estáis equivocados”, frase esta última que sí aparece en la película.

bajo el control científico de esta empresa y sujeta a la inspección y normas de la Dirección General de Sanidad". $A B C, 15-\mathrm{V}-1954$.

33 Hubo bastantes investigadores implicados en el descubrimiento de la estreptomicina, como los del área química, los médicos William F. Feldman y H. Cornwin Hinshaw, Elizabeth Bugie y, sobre todo, Albert Schatz; todos ellos fueron silenciados por Selman Abraham Waksman, utilizando los medios a su alcance; en 1952 Waksman recibió el Premio Nobel, en solitario, por el descubrimiento de este antibiótico (Wainwright, 1992, pp. 161172).

34 Se trata de un antibiótico de amplio espectro, obtenido a partir de Streptomyces venezuelae, que pronto quedó restringido debido a su toxicidad (anemia aplásica). Fue sintetizado por el científico de la Universidad de Yale (EE.UU.) Paul Rufus Burkholder, con la colaboración de la empresa farmacéutica norteamericana Parke Davis (Wainwright, 1992, pp. 190-191). 
En la conversación mantenida entre el inspector de policía y Chambón, otro de los contrabandistas, se manifiesta que esta estreptomicina probablemente procedía del robo en un hospital militar estadounidense, un suceso que provocó la muerte de dos policías que intentaron evitar la sustracción, y que también se utilizaba como explicación del origen de la penicilina de contrabando en la Viena de El tercer hombre. En 1947 el precio de la estreptomicina 'oficial' debía estar en torno a las 225 pesetas/gramo, aunque en el mercado negro se vendía a más de mil pesetas, según se desprende de algunos comentarios aparecidos en la prensa periódica35.

Una serie de acontecimientos obligan al protagonista de Mercado prohibido a ocultarse de la justicia ante una acusación de asesinato. El negocio clandestino queda en manos de Daniel, personaje sin escrúpulos que no dudará en negarle a su antiguo jefe el cloranfenicol que necesita para salvar la vida de su hijo, enfermo de 'tifus'36; tal vez en referencia al tifus exantemático epidémico, la 'enfermedad del piojo verde', habitual durante los años de la postguerra en España (Jiménez Lucena, 1994), aunque también pudiera tratarse de fiebres tifoideas. Para ambas enfermedades era válido este tratamiento (Abraham \& Phil, 1951).

Finalmente, German acaba consiguiendo el cloranfenicol gracias a otro contrabandista, al que paga 63.00o pesetas, todo lo que tiene, por un envase que acaba perdiendo cuando la policía hace su aparición justo en el momento

\footnotetext{
35 “También trafican con la estreptomicina (...) 'Informaciones' publica lo siguiente: 'No hacemos más que preguntar. La persona que nos comunica lo que vamos a decir nos merece entero crédito por si misma y por las precisiones que acompaña a su comunicación. Así y todo preguntamos: ¿Es verdad que el precio 'oficial' de la estreptomicina es de 225 pesetas el gramo? ¿Es verdad que esta insubstituible droga puede adquirirse, si se importa directamente al precio de 50 pesetas el gramo? ¿Es verdad que pueden vender esta droga los almacenistas de quincalla al por mayor, como nos afirma nuestro comunicante, que la adquirió en uno de esos almacenes? ¿Es verdad que, además en el 'mercado negro' se venda la estreptomicina a más de mil pesetas el gramo? Finalmente el periódico se dirige a las autoridades y las excita contra la codicia de los traficantes de esa droga". La Vanguardia Española, 12/10/1947.

${ }^{36}$ En el guion, Germán se entera de la naturaleza de la enfermedad que aqueja a su hijo gracias a una conversación -eliminada en la película- mantenida con un farmacéutico francés, quien le informa que la cloromicetina se emplea para el 'tifus', se trataba de un medicamento recién descubierto, difícil de encontrar como no fuera de contrabando en lugares como Calais o Marsella. (Julio Coll, José Germán Huici. 1951. Op. cit. AGA, (o3) 49.02, caja 9714).
} 
de la transacción 37 . La situación la resolverá Lola, su amante, una femme fatale a la española, cantante de copla, apodada 'La Lucky' en alusión a su refinado gusto por esta especial marca de tabaco, también unida al contrabando, depositaria de otro envase de cloranfenicol que ese mismo contrabandista, jefe del local donde ella trabaja, le entrega a cambio de algún tipo de favor sexual que, evidentemente, apenas queda sugerido en la película. 'La Lucky', profundamente enamorada de Germán, le entrega a éste el cloranfenicol, de forma gratuita, que el protagonista acepta no sin pasar antes por unos momentos de duda ante la posibilidad de que fuera un producto adulterado o falsificado.

El antibiótico es suministrado y su hijo comienza a curarse, sin embargo, el médico explica que necesita una segunda unidad para lograr salvarlo38. Cuando ya todo parece perdido, hace su aparición el inspector de policía que, en un alarde de comprensión y sensibilidad humana, en el que no es difícil vislumbrar una actitud a favor de este grupo profesional, entrega a Germán el envase de cloranfenicol que había perdido en el momento de su frustrado arresto. El niño finalmente salva la vida, aunque Germán tiene que pagar por los actos delictivos cometidos; una circunstancia que, a juzgar por la última secuencia, en la que Germán acompaña voluntariamente al inspector, se nos quiere mostrar más como penitencia por los pecados cometidos que como castigo de naturaleza penal.

37 La cantidad inicial solicitada por el contrabandista a Germán, por un envase de cloranfenicol, fue 100.000 pesetas; en el guion la cifra pedida ascendía a las 50.000 pesetas, de las cuales Germán pagó sólo 47.000 pesetas (Julio Coll, José Germán Huici. 1951. Op. cit. AGA, (03) 49.02, caja 9714).

${ }^{38}$ Según Florencio Bustinza (1949b), este medicamento era eficaz contra "la fiebre tifoidea, fiebre de Malta, tifus exantemático y en algunas otras enfermedades; pero la cloromicetina no es ninguna panacea universal; no es un cúralo todo como tampoco lo es la maravillosa penicilina. Estos medicamentos antibióticos tienen acción selectiva sobre determinados microbios y virus [sic], y por lo tanto solamente sirven para el tratamiento de determinadas enfermedades (...)" En cuanto a su presentación, venía en frascos de doce cápsulas con 0,25 gramos de producto en cada una. La dosis inicial solía ser de 60 miligramos por kilo de peso del enfermo, es decir, entre tres y cuatro gramos para un adulto, en tres tomas distanciadas una hora cada una; después, se continuaría la medicación con una cápsula de 0,25 gramos cada tres horas hasta que remitiera la fiebre; el tratamiento habría que mantenerlo, con dosis de o,25 gramos cada cuatro horas, durante 24-48 horas mínimo, aunque a veces se prolongaba durante siete u ocho días. 


\section{Conclusión}

Aunque la película pasara desapercibida para el público al que fue destinada, se ha convertido en una sutil y adecuada fuente para acercarnos a uno de los más sórdidos episodios del comercio de los medicamentos, ese floreciente 'mercado prohibido' que durante los años del franquismo autárquico supuso el negocio ilegal de la penicilina y otros antibióticos.

La adecuada acomodación del guion de esta película a la situación de este problema social, económico y sanitario, vislumbrada a través de las noticias de la prensa periódica y profesional, la convierte en un magnífico ejemplo visual y nos permite conocer una nueva perspectiva, esta vez desde la mirada del usuario, del tráfico de medicamentos durante los años del franquismo.

\section{Referencias bibliográficas}

Abraham, E. P. \& Phil, D. (1951). Cloramfenicol, Aureomicina, Terramicina y Neomicina. Farmacia Nueva, 16(174), 319-321; 16(175), 367-375.

Agencia EFE (1944). Penicilina para todo el mundo. $A B C, 1 / 07 / 1944$.

Agencia EFE (2001). José Germán Huici, guionista cinematográfico. El País, 25/06/2001.

Álvarez Sierra, J. (1944). Lo que cura la penicilina. Presente y porvenir de una droga mágica. Madrid: Afrodisio Aguado.

Anuario del Cine Español. ([1955]). Madrid: SNE.

Aracena Badillos, C. (2007). Un colorista y poliédrico laberinto. Los largos años 50 (1951-1962). Madrid: Liceus.

Bellot Rodríguez, F. ([1982]). Don Florencio Bustinza Lachiondo. Trabajos del Departamento de Botánica y Fisiología Vegetal, 11, 9-15.

Bustinza, F. (1945). De Pasteur a Fleming. Los antibióticos antimicrobianos y la Penicilina. $4^{\mathrm{a}}$ ed. Madrid: Plus-Ultra.

Bustinza, F. (1948). La Estreptomicina. Farmacia Nueva, 13(142), 573-575.

Bustinza, F. (1949a). Sobre algunas definiciones y conceptos fundamentales en relación con la penicilina. Farmacia Nueva, 14(146), 128-129.

Bustinza, F. (1949b). La Cloromicetina. Farmacia Nueva, 14(155), 630-632.

Comas Puente, A. (2002). IFI, Sociedad Anónima, empresa cinematográfica y escuela de cineastas y su artífice, Ignacio F. Iquino [tesis doctoral]. Barcelona: Universitat Autònoma de Barcelona.

Córdoba, C.V. (1982). Florencio Bustinza Lachiondo (7-X-1902 / 10-1-1982). Anales del Jardín Botánico de Madrid, 39(1), 3-8.

Crusells, M. (2009). Directores de cine en Cataluña: de la A a la Z. Barcelona: Publicacions i Edicions, Universitat de Barcelona.

Fleming, A. (1948). Cómo debe usarse la penicilina. Conferencia pronunciada en el Teatro Español de Madrid por el Profesor Sir Alexander Fleming, 
el día 12 de junio de 1948. Farmacia Nueva, 13(138): 370-378.

Fonfría Díaz, J. (2013). Florencio Bustinza Lachiondo (1902-1982) y los antibióticos. En: A. González Bueno \& A. Baratas Díaz (Eds.) La Tutela Imperfecta. Biología y Farmacia en la España del primer franquismo (pp. 295-340). Madrid: CSIC.

García Sánchez, J. E. \& García Sánchez, E. (2004). Antibióticos y cine: El tercer hombre y Mercado prohibido. Revista Española de Quimioterapia, 17(3), 223-225.

García Sánchez, J. E., García Sánchez, E. \& Merino Marcos, M.L. (2006). Antibacterial agents in the cinema. Revista Española de Quimioterapia, 19(4), 397-402.

González Bueno, A. \& Rodríguez Nozal, R. (2012). La penicilina en la España franquista: importación, intervención e industrialización. Eidon, 38 (diciembre), edición on-line. http://www.revistaeidon.es [fecha de consulta: 27/05/2015]).

Jiménez Lucena, I. (1994). El tifus exantemático de la posguerra española (1939-1943). El uso de una enfermedad colectiva en la legitimación del 'Nuevo Estado'. Dynamis, 14, 185-198.

Olagüe de Ros, G. (2001). Del uso de la retórica en el discurso científico: a propósito de los programas de trabajo de Fidel Fernández Martínez (1890-1942) y Eduardo Ortiz de Landázuri (1910-1985). Granada: Real Academia de Medicina y Cirugía de Granada.

[Redacción]. (1946). La distribución de penicilina. Farmacia Nueva, 11(112), 244.

[Redacción]. (1948). Díganos usted algo... ¿Qué se sabe de la penicilina? Farmacia Nueva, 13(140), 479-780.

[Redacción]. (1950). Los nuevos 'malos'. Farmacia Nueva, 15(159), [s.p.]

[Redacción]. (1951). El 'Cuarto hombre'. Farmacia Nueva, 16(168), 20-21.

[Redacción]. (1958). Distribución y precios de los antibióticos. Farmacia Nueva, 23(255), 175-176.

Rodríguez Nozal, R. (2004). Uriach, Cambronero, Gallego. Farmacia e Industria. La producción de los primeros medicamentos en España. Madrid: Nivola.

Rodríguez Nozal, R. (2011). ¿Fortuna o desdicha? La entrada de la penicilina en la España de la autarquía, un nuevo desafío para la farmacia y la industria farmacéutica. En: A. González Bueno et al. (Ed.), Homenaje al Prof. Dr. José Luis Valverde (pp. 515-550). Granada: Universidad de Granada / SDUHFE.

Rubio Gijón, P. (2014). Crímenes contra el Estado: el género policial fílmico en la España de la segunda década de la autarquía (1950-1959) y en la Argentina del primer peronismo (1946-1955) [tesis doctoral]. Vancouver: The University of British Columbia.

Sánchez Barba, F. (2007). Brumas del franquismo. El auge del cine negro español (1950-1965). Barcelona: Publicacions i Edicions de la Universitat de Barcelona. 
Santesmases, M.J. (1999). Antibióticos en la Autarquía: banca privada, industria farmacéutica, investigación científica y cultura liberal en España, 1940-1960. Madrid: Fundación Empresa Pública.

Santesamases, M.J. (2011). An antibiotic screening programme: in search of antagonism in the 1950s. En: A. Romero, C. Gradmann \& M.J. Santesmases (Eds.) Circulation of Antibiotics: Journeys of Drug Standars, 1930-1970 (pp. 123-139. Madrid: Centro de Ciencias Humanas y Sociales (CSIC).

Simón Sanjurjo, J. A. (2012). Fútbol y cine en el franquismo: la utilización política del héroe deportivo en la España de Franco. Historia $y$ Comunicación Social, 17, 69-84.

Vandaele, J. (2015). Estados de Gracia: Billy Wilder y la censura franquista (1946-1975). Leiden: The Brill Rodopi.

Volpone [pseudónimo de Pío del Busto Medrano]. (1946). Hablando con la señorita Rosa Gómez, encargada del Servicio de la Penicilina. Farmacia Nueva, 11(108), 29-32.

Wainwright, M. (1992). Cura milagrosa. Historia de los antibióticos. Barcelona: Pomares-Corredor. 